\title{
Efeito do tamanho da presa e do acréscimo de ração na larvicultura de pacamã ${ }^{1}$
}

\section{Marcelo Mattos Pedreira ${ }^{2}$, José Cláudio Epaminondas dos Santos ${ }^{3}$, Edson Vieira Sampaio ${ }^{3}$, Felipe Nilvan Pereira ${ }^{4}$, Janaina de Lima Silva ${ }^{4}$}

\footnotetext{
${ }^{1}$ Projeto financiado pela Fapemig e pelo CNPq.

2 Departamento de Zootecnia da Universidade Federal dos Vales do Jequitinhonha e Mucuri - UFVJM.

${ }^{3}$ Estação de Hidrobiologia e Piscicultura de Três Marias da Companhia de Desenvolvimento dos Vales do São Francisco e Parnaíba CODEVASF.

${ }^{4}$ Curso de Zootecnia da Universidade Federal dos Vales do Jequitinhonha e Mucuri - UFVJM.
}

RESUMO - Objetivou-se estudar o efeito do tamanho da presa, com ou sem adição de ração na larvicultura do pacamã (Lophiosilurus alexandri), espécie nativa da bacia do Rio São Francisco ameaçada de extinção. As larvas foram cultivadas em aquários por 16 dias e alimentadas com zooplâncton natural, selecionado em malhas de 650 e $1.300 \mu$ m, com ou sem ração. A oferta de zooplâncton de maior tamanho resultou em melhor desenvolvimento das larvas de pacamã, comprovando a vantagem do fornecimento de partículas alimentares maiores para o potencial de crescimento da espécie. O aumento na quantidade de ração não influenciou o desempenho das larvas, evidenciando a baixa ou falta de capacidade das larvas em digerir a ração ofertada. O fornecimento de ração diminuiu o pH e aumentou a condutividade elétrica, prejudicando a qualidade da água, o que não afetou o desempenho das larvas.

Palavras-chave: cultivo de larvas, espécie nativa, extinção, manejo alimentar, repovoamento, sistema intensivo

\section{Effect of prey size selection and feeding on the larviculture of pacamã}

\begin{abstract}
The effect of prey size selection and feeding on pacamã Lophiosilurus alexandri larvae culture (native specie of San Francisco basin classified as threatened of extinction) was evaluated. The larvae were cultivated in aquariums during 16 days and fed with natural zooplankton, screened in 650 and $1300 \mu \mathrm{m}$ sieve, with and without ration. The offer of zooplankton of largest size provided a better development of the pacamã larvae, demonstrating the need of alimentary particles larger for the growth potential of the species. The increase of the amount of ration did not affect the performance of the larvae, evidencing low or lack of capacity in digesting the offered ration. The ration fed reduced the $\mathrm{pH}$ and increased the electric conductivity, worsening water quality, which did not affect the performance of the larvae.
\end{abstract}

Key Words: extinction, handling to feed, intensive system, larvae culture, native specie, settlement

\section{Introdução}

O pacamã (Lophiosilurus alexandri), espécie nativa e endêmica da Bacia Hidrográfica do Rio São Francisco (Sato et al., 1987; Sato \& Godinho, 1999), presumivelmente ameaçada de extinção (Lins, 1997), tem despertado crescente interesse em virtude de sua importância na pesca artesanal (Godinho et al., 2003) e de seus promissores resultados na aqüicultura, uma vez que responde positivamente ao manejo reprodutivo (Sato et al., 2003), possibilitando resultados positivos em programas de repovoamento (Sato \& Sampaio, 2005).

Diversas pesquisas têm comprovado que a alimentação, especialmente o plâncton nativo na fase larval, é um entrave para a produção de alevinos, pois em vez de servir de alimento, muitas vezes, o plâncton compete ou preda as larvas, como ocorrem nas criações do pintado (Behr et al., 1997), da piracanjuba (Pedreira \& Sipaúba-Tavares, 2002), do tambaqui e pacu (Fregadolli, 2003), do matrinxã (Pedreira et al., 2006) e de outros peixes. Apesar desse inconveniente, a oferta de plâncton coletado em tanques ainda é empregada, pois a utilização da artêmia é de custo elevado.

Além disso, no início da alimentação exógena, muitas larvas não apresentam o trato digestório desenvolvido o suficiente para assimilar ração (Dabrowski, 1984). Nesses casos, para reduzir o tempo de dependência do plâncton e acelerar a introdução da ração, tem-se associado a ração com o plâncton, o que tem proporcionado melhores rendi- 
mentos na larvicultura de piracanjuba (Pedreira \& SipaúbaTavares, 2002) e dourado (Vega-Orellana et al., 2006). Outro recurso é o uso da ração suplementada com enzimas para facilitar sua digestibilidade, como verificado com larvas de pacu Piaractus mesopotamicus (Tesser et al., 2006).

O tamanho do plâncton ofertado também pode determinar melhores rendimentos no cultivo de larvas e diminuir o canibalismo, como observaram Pedreira \& Sipaúba-Tavares (2002) no cultivo de piracanjuba. As características e as respostas podem variar em condições específicas, no entanto, para se conhecer a capacidade da larva do pacamã em assimilar ração e o efeito do tamanho do zooplâncton no rendimento das larvas, é necessária investigação mais detalhada.

Este trabalho foi realizado com o objetivo de estudar o efeito do tamanho da presa e do fornecimento de ração na larvicultura de pacamã.

\section{Material e Métodos}

O experimento foi realizado durante 16 dias, em fevereiro de 2006, na Estação de Hidrobiologia e Piscicultura de Três Marias - EPT, da Companhia de Desenvolvimento dos Vales do São Francisco e do Parnaíba - CODEVASF, em Três Marias, Minas Gerais. Foram utilizadas larvas irmãs de pacamã, com sete dias de vida, com peso e comprimento totais médios de 23,53 mg e 1,33 cm, respectivamente, obtidas na CODEVASF.

As larvas foram contadas individualmente e distribuídas em aquários de $7 \mathrm{~L}$, cada um com $5 \mathrm{~L}$ de água, em densidade de 15 larvas por litro (75 larvas/aquário). Os aquários foram mantidos sob aeração constante e luminosidade, obtida pelo fotoperíodo natural.

Diariamente, às $7 \mathrm{~h} 10$, foram tomadas medidas de oxigênio dissolvido ( $\mathrm{mg} / \mathrm{Le} \%$ de saturação), $\mathrm{pH}$, condutividade elétrica $(\mu \mathrm{S} / \mathrm{cm})$ e temperatura da água $\left({ }^{\circ} \mathrm{C}\right)$ de cada aquário. Após a leitura das variáveis limnológicas, realizaram-se a sifonagem dos aquários para remoção dos dejetos e a troca de $20 \%$ do volume de água.

As larvas de pacamã foram submetidas a quatro regimes alimentares, cada um com cinco repetições. Os regimes alimentares consistiram do fornecimento de plâncton natural selecionado em peneira de malha com 650 ou $1.300 \mu \mathrm{m}$ de abertura, com ou sem ração. As larvas foram alimentadas, à vontade, uma vez ao dia com plâncton vivo e duas vezes ao dia (8 e 14 h) com ração (Tabela 1).

O zooplâncton foi capturado em viveiros adubados, com rede de malha $(68 \mu \mathrm{m})$, colocado em um frasco em 4,0 L e triado em peneira de malha com $1.300 \mu \mathrm{m}$ de abertura.
Tabela 1 - Composição da ração comercial fornecida às larvas de pacamã (Lophiosilurus alexandri) durante 16 dias

\begin{tabular}{lc}
\hline Componente & $\%$ \\
\hline Proteína bruta & $\geq 36,0$ \\
Umidade máxima & $\leq 13,0$ \\
Extrato etéreo & $\geq 3,5$ \\
Fibra & $\leq 7,0$ \\
Minerais & $\leq 10,0$ \\
Cálcio & $\leq 1,5$ \\
Fósforo & $\geq 0,5$ \\
\hline
\end{tabular}

Metade desse volume (2,0 L) foi transferida para outro frasco e triada em peneira de malha com $650 \mu \mathrm{m}$ de abertura. Em seguida, o zooplâncton foi homogeneizado e distribuído entre os aquários (200 mL para cada aquário).

Ao término do cultivo, todo o zooplâncton de cada aquário foi concentrado em rede de $68 \mu \mathrm{m}$ e colocado em um frasco de $250 \mathrm{~mL}$ para fixação e conservação em solução de formalina a $10 \%$. Posteriormente, foram escolhidos aleatoriamente seis aquários do tratamento com zooplâncton triado em peneiras de $650 \mu \mathrm{m}$, com ou sem ração, e outros seis do zooplâncton triado em peneiras de $1.300 \mu \mathrm{m}$, com ou sem ração. De cada aquário selecionado foi retirada uma amostra de $1 \mathrm{~mL}$ e sob microscópio estereoscópio o zooplâncton foi caracterizado quali e quantitativamente. $\mathrm{O}$ número dos organismos ofertados em cada regime alimentar $(650$ e $1.300 \mu \mathrm{m})$ foi comparado por ANOVA, com nível de significância de 0,05. Para comparar o comprimento do zooplâncton ofertado, 30 exemplares de copépodos, cladóceros e náuplios de cada tratamento foram mensurados em microscópio estereoscópio com ocular micrométrica e as medidas foram comparadas por ANOVA, com nível de significância de 0,05 .

Ao término do experimento, as larvas foram fixadas e conservadas em solução de formalina a $10 \%$ para posterior biometria. No laboratório, foram contadas individualmente para cálculo da taxa de sobrevivência e da biomassa, obtida pela pesagem de todas as larvas de cada repetição em balança analítica com $0,1 \mathrm{mg}$ de precisão.

O comprimento total e o peso médio de dez larvas de cada repetição foram obtidos com paquímetro e uma balança analítica, respectivamente. Em seguida, foi calculado o fator de condição de Fulton Fulton $(\mathrm{K}=$ peso $\times 100 /$ comprimento total ${ }^{3}$ ).

A avaliação do efeito dos regimes alimentares foi realizada pela comparação dos valores médios das larvas e pela aplicação da ANOVA e do teste Tukey a 0,05 de significância. As variáveis limnológicas dos tratamentos foram comparadas por Kruskal-Wallis e pelo teste Student Newman Keuls a 0,05 de significância. 


\section{Resultados e Discussão}

As larvas de pacamã alimentadas com plâncton selecionado em redes de $1.300 \mu \mathrm{m}$ apresentaram melhor rendimento (peso, biomassa, tamanho e fator de condição) em comparação às alimentadas com plâncton selecionado em peneiras de $650 \mu \mathrm{m}$ (Tabelas 2, 3 e 4 ). O fornecimento de ração não melhorou o rendimento do cultivo, uma vez que os parâmetros biológicos amostrados foram semelhantes entre si, no entanto, a ração alterou a qualidade da água, aumentando sua acidez e condutividade (Tabela 5) e tornando-a um ambiente redutor, no qual as partículas em suspensão, além de diminuírem a capacidade da água de reter oxigênio, ao serem decompostas, aumentam a concentração de amônia Shäfer (1985), que é tóxica às larvas.

A alteração da qualidade da água pela decomposição da ração é prejudicial à larvicultura de peixes. Smerman et al. (2002) observaram a necessidade de remover de modo mais eficiente e rápido os dejetos do arraçoamento. Segundo os autores, a taxa de sobrevivência de larvas de pintado (Pseudplatystoma sp.) foi baixa, em virtude da quantidade de dejetos de ração e do tipo de ração, que pode apresentar maior ou menor estabilidade na água, conforme sua composição. Esses autores observaram também que a ração de farinha de sangue + plâncton foi mais estável na água que a farinha de sangue e de carne + plâncton, o que proporciona maior sobrevivência e facilidade para limpeza.

Os menores valores absolutos de sobrevivência foram observados nos aquários em que larvas receberam ração. $\mathrm{O}$ fornecimento de ração aumentou a condutividade elétrica e diminuiu os valores do $\mathrm{pH}$ (Tabela 5), o que provocou mortandade. A qualidade da água e sua estabilidade são fatores determinantes do sucesso na larvicultura de peixes, principalmente em sistemas intensivos (Kamler, 1992). Neste experimento, o sifonamento diário seguido de reno- vação parcial da água foi a medida de rotina adotada para a manutenção da qualidade da água. Provavelmente, uma filtração prévia da água com filtros mecânicos de pequena porosidade, como os de 3 e $5 \mu \mathrm{m}$, e carvão ativado utilizados por Pedreira et al. (2006) ou com filtros de areia de 2 a $5 \mu \mathrm{m} \mathrm{de}$ diâmetro ou biofiltros, como sugerido por Tucker Jr. (1998) melhoraria o ambiente de cultivo.

O tamanho e a disponibilidade dos organismos planctônicos influenciam na captura das presas e no sucesso do cultivo de larvas de alguns espécimes nativos, como piracanjuba (Pedreira \& Sipaúba-Tavares, 2002), matrinxã (Pedreira \& Sipaúba-Tavares, 1999) e tambaqui (Pedreira \& Sipaúba-Tavares, 1998). López \& Sampaio (2000) submeteram larvas de pacamã a três densidades de estocagem e observaram que 0 aumento da densidade de 150 larvas $/ 0,43 \mathrm{~m}^{2}$ para 500 larvas $/ 0,43 \mathrm{~m}^{2}$ interferiu negativamente na taxa de sobrevivência. Os autores sugeriram que a redução da taxa de sobrevivência foi consequiência do aumento da densidade populacional, que intensificou a competição por alimento e espaço, resultando em canibalismo. Como nesta pesquisa não foi observado canibalismo, acredita-se que a disponibilidade de alimento e de espaço foi suficiente.

Larvas de várias espécies inicialmente apresentam pequena abertura de boca, que possibilita o consumo de presas pequenas (Hunter, 1984). Contudo, essa afirmação não é verdadeira para algumas espécies. Pedreira \& SipaúbaTavares (2002) observaram que larvas de piracanjuba que apresentam canibalismo se alimentando de larvas até do mesmo porte, quando alimentadas com plâncton menor que $350 \mu \mathrm{m}$, apresentaram maior taxa de sobrevivência em comparação às alimentadas com organismos planctônicos selecionados em peneiras com tamanho de malha de $1.000 \mu \mathrm{m}$. Os autores relacionaram esses melhores resultados à condição mais uniforme de alimentação e ao crescimento das larvas, que diminui a probabilidade de canibalismo.

Tabela 2 - Composição do plâncton fornecido durante 16 dias a larvas de pacamã (Lophiosilurus alexandri)

\begin{tabular}{|c|c|c|c|c|}
\hline Item & $\begin{array}{c}\leq 650 \mu \mathrm{m} \\
\text { Itens/100 mL }\end{array}$ & $\begin{array}{l}\leq 1.300 \mu \mathrm{m} \\
\text { Itens } / 100 \mathrm{~mL}\end{array}$ & $\begin{array}{l}\leq 650 \mu \mathrm{m} \\
\text { Itens }(\%)\end{array}$ & $\begin{array}{l}\leq 1.300 \mu \mathrm{m} \\
\text { Itens }(\%)\end{array}$ \\
\hline \multicolumn{5}{|l|}{ Copépodo } \\
\hline Adulto e copepodito & $318,4 \pm 27,2 b$ & $553,6 \pm 81,6 a$ & $30,5 \pm 2,6 b$ & $53,0 \pm 7,8 \mathrm{a}$ \\
\hline Fêmea ovada & $44,8 \pm 22,5 \mathrm{a}$ & $88,8 \pm 37,4 a$ & $4,3 \pm 2,2 \mathrm{a}$ & $8,5 \pm 3,6 a$ \\
\hline Náuplio & $408,8 \pm 23,4 \mathrm{a}$ & $279,2 \pm 86,7 b$ & $39,2 \pm 2,2 \mathrm{a}$ & $26,7 \pm 8,3 b$ \\
\hline \multicolumn{5}{|l|}{ Cladócero } \\
\hline Sem neonata & $264,0 \pm 20,4 a$ & $304,0 \pm 78,1 \mathrm{a}$ & $25,3 \pm 2,0 \mathrm{a}$ & $29,1 \pm 7,5 \mathrm{a}$ \\
\hline Com neonata & $26,4 \pm 8,3 b$ & $53,6 \pm 19,1 \mathrm{a}$ & $2,5 \pm 0,8 b$ & $5,1 \pm 1,8 \mathrm{a}$ \\
\hline Exúvia de crustáceo & $10,4 \pm 3,6 \mathrm{a}$ & $12,0 \pm 7,5 \mathrm{a}$ & $1,0 \pm 0,3 \mathrm{a}$ & $1,1 \pm 0,7 \mathrm{a}$ \\
\hline Rotífero & $1,6 \pm 2,2 \mathrm{a}$ & $8,8 \pm 7,7 a$ & $0,2 \pm 0,2 \mathrm{a}$ & $0,8 \pm 0,7 a$ \\
\hline Ovo & $4,8 \pm 3,3 \mathrm{a}$ & $8,0 \pm 2,8 \mathrm{a}$ & $0,5 \pm 0,3 \mathrm{a}$ & $0,8 \pm 0,3 \mathrm{a}$ \\
\hline Inseto & $0,0 \pm 0,0 \mathrm{a}$ & $2,4 \pm 3,6 a$ & $0,0 \pm 0,0 \mathrm{a}$ & $0,2 \pm 0,3 \mathrm{a}$ \\
\hline Total & $1.079,2 \pm 79,9 \mathrm{a}$ & $1.310,4 \pm 318,7 \mathrm{a}$ & & \\
\hline
\end{tabular}

Médias na mesma linha e variável seguidas de letras distintas diferem $(P<0,05)$ significativamente segundo ANOVA. 
Luz \& Zaniboni-Filho (2001) também sugeriram que o fornecimento do zooplâncton como alimento pode controlar o canibalismo desde que seu manejo e sua composição estejam adequados.

No entanto, a larva de pacamã não é uma espécie tipicamente canibal, apesar de apresentar boca proporcionalmente grande. Neste experimento, embora o número total de organismos zooplanctônicos ofertados às larvas tenha sido praticamente o mesmo entre zooplâncton selecionado em 1.300 e $650 \mu \mathrm{m}$ (Tabela 2), o plâncton selecionado em $1.300 \mu \mathrm{m}$ proporcionou melhor crescimento e fator de condição, além de taxa de sobrevivência de 92,4\%. Isso pode ser explicado pela maior biomassa, pois o zooplâncton selecionado em peneira de $1.300 \mu \mathrm{m}$ apresentou mais copépodos, e de maior porte, enquanto o zooplâncton selecionado em peneira de $650 \mu \mathrm{m}$ possuía maior número de náuplios, organismos de pequeno porte (Tabelas 2 e 3 ).

Tabela 3 - Comprimento do zooplâncton oferecido a larvas de pacamã (Lophiosilurus alexandri) cultivadas durante 16 dias

\begin{tabular}{lcc}
\hline & $\begin{array}{c}\leq 650 \mu \mathrm{m} \\
\text { Comprimento }(\mathrm{mm})\end{array}$ & $\begin{array}{c}\leq 1300 \mu \mathrm{m} \\
\text { Comprimento }(\mathrm{mm})\end{array}$ \\
\hline Copépodo & $0,79 \pm 0,17 \mathrm{~b}$ & $0,94 \pm 0,11 \mathrm{a}$ \\
Cladócero & $0,56 \pm 0,15 \mathrm{a}$ & $0,63 \pm 0,18 \mathrm{a}$ \\
Náuplio & $0,21 \pm 0,03 \mathrm{a}$ & $0,20 \pm 0,03 \mathrm{a}$ \\
\hline
\end{tabular}

Médias na mesma linha seguidas de letras distintas diferem $(P<0,05)$ significativamente segundo ANOVA.
Santos et al. (2003) também observaram taxa de sobrevivência similar $(92,2 \%)$ para larvas de pacamã alimentadas com plâncton coletado em tanques adubados, em experimento também conduzido em Três Marias em densidade de 6,24 larvas/L. Neste estudo, o aumento do tamanho da presa para as larvas de pacamã otimizou a relação custo/benefício, que, segundo Kamler (1992) e Duray et al. (1997), aumenta de forma inversamente proporcional ao tamanho da presa.

$\mathrm{O}$ fato de o fornecimento de ração não ter interferido no rendimento pode ser parcialmente explicado pela falta ou pela baixa capacidade da larva em digerir alimento seco no início da alimentação exógena. Este fenômeno está relacionado às características morfológicas do trato digestivo e das enzimas secretadas ao longo do desenvolvimento (Dabrowski, 1984). Larvas de pacu, piauçu, tambaqui, dourado, curimbatá, matrinxã, piraputanga e piracanjuba, characiformes e carpa Cyprinus carpio, cipriniformes, não assimilam dietas artificiais por apresentarem trato digestivo rudimentar, que exige de algumas enzimas digestivas (Oliveira et al., 2004). Larvas de characiformes alimentadas exclusivamente com ração geralmente apresentam baixas taxas de sobrevivência e menor porte em comparação àquelas alimentadas com plâncton ou plâncton + ração, fato observado por Pedreira \& Sipaúba-Tavares (1998) em experimento com tambaqui (Colossoma macropomum) e Pedreira \& Sipaúba-Tavares (1999) em pesquisa com matrinxã (Brycon cephalus). Essas larvas necessitariam de

Tabela 4 - Parâmetros biométricos de larvas de pacamã (Lophiosilurus alexandri) alimentadas por 16 dias com zooplâncton, sem e com ração

\begin{tabular}{|c|c|c|c|c|}
\hline & $\begin{array}{l}\leq 650 \mu \mathrm{m} \\
\text { Plâncton }\end{array}$ & $\begin{array}{l}\leq 650 \mu \mathrm{m} \\
\text { Plâncton e ração }\end{array}$ & $\begin{array}{l}\leq 1.300 \mu \mathrm{m} \\
\text { Plâncton }\end{array}$ & $\begin{array}{c}\leq 1.300 \mu \mathrm{m} \\
\text { Plâncton e ração }\end{array}$ \\
\hline Sobrevivência (\%) & $88 \pm 6,4 a$ & $53 \pm 48,8 \mathrm{a}$ & $92 \pm 1,3 \mathrm{a}$ & $73 \pm 34,6 a$ \\
\hline Peso (mg) & $75,6 \pm 4,52 b$ & $72,1 \pm 2,09 b$ & $125,8 \pm 16,63 a$ & $122,0 \pm 6,16 \mathrm{a}$ \\
\hline Comprimento total $(\mathrm{cm})$ & $2,2 \pm 0,05 b$ & $2,2 \pm 0,03 b$ & $2,5 \pm 0,12 \mathrm{a}$ & $2,4 \pm 0,06 \mathrm{a}$ \\
\hline Comprimento padrão $(\mathrm{cm})$ & $1,7 \pm 0,04 b$ & $1,6 \pm 0,01 b$ & $1,9 \pm 0,10 \mathrm{a}$ & $1,8 \pm 0,05 \mathrm{a}$ \\
\hline
\end{tabular}

Médias na mesma linha, seguidas de letras distintas diferem $(P<0,05)$ significativamente segundo o teste Tukey.

Tabela 5 - Características limnológicas da água de cultivo de larvas de pacamã (Lophiosilurus alexandri) alimentadas por 16 dias com zooplâncton, sem e com ração

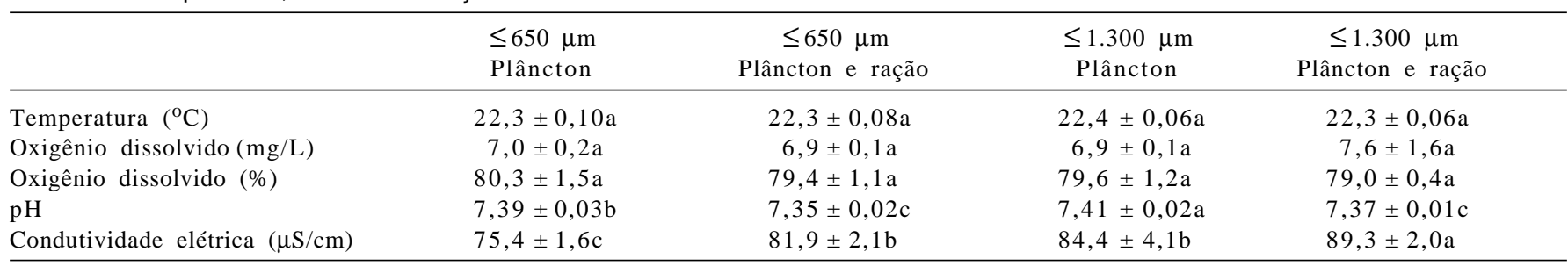

Médias na mesma coluna seguidas de letras distintas diferem significativamente segundo o teste Student-Newman-Keuls $(P<0,05)$. 
alimento vivo, o qual forneceria as enzimas complementares para a atividade proteolítica efetiva. A atividade enzimática em rotíferos e artêmia é equivalente ou superior à das larvas de Mugil platanus, portanto, segundo Galvão et al. (1997), a atividade de enzimas exógenas é importante nas primeiras etapas do desenvolvimento. Esses autores verificaram ainda que a ingestão de alimento vivo induz o aumento da atividade enzimática em tainhas juvenis.

Kolkovski et al. (1997), cultivando Dicentrarchus labrax, verificaram que o fornecimento de náuplio de artêmia favoreceu a digestão da ração, resultando em maior crescimento das larvas. Esses autores descreveram quatro hipóteses para explicar a melhor assimilação da ração: as enzimas digestivas do próprio náuplio de artêmia auxiliariam na digestão larval; o alimento vivo ajudaria ao processo digestivo larval por meio de uma contribuição dos hormônios gástricos, que podem melhorar a ativação gástrica da larva; os náuplios influenciariam na assimilação e absorção de ingredientes da ração por meio de lipídeos polares e/ou outras frações; e o estímulo visual ou olfatório pode estar associado ao aumento do peristaltismo e do processo digestivo larval.

Segundo Oliveira et al. (2004), enzimas liberadas durante a ingestão do plâncton desencadeiam a hidrólise das proteínas do próprio plâncton e estimulam a secreção das enzimas endógenas das larvas, facilitando a digestão e assimilação. Esse processo provavelmente interfere positivamente na absorção do alimento inerte, como sugerido por Pedreira \& Sipaúba-Tavares (2002), em estudo com larvas de piracanjuba, Pedreira \& Sipaúba-Tavares (1998), em pesquisa com larvas de piracanjuba, e Pedreira \& Sipaúba-Tavares (1999), com larvas de matrinxã. Esses autores observaram que uso de plâncton e ração proporcionou melhor rendimento em comparação ao uso exclusivo de plâncton.

Essa hipótese também foi descrita por Vega-Orellana et al. (2006), que, em pesquisa com larvas de dourado Salminus brasiliensism, observaram aceitação de uma dieta artificial pelas larvas a partir do quinto dia, quando ainda era oferecido plâncton. Segundo os autores, é aconselhável começar o processo de substituição do plâncton pela ração nesse período. Essa transição deve ser feita de forma gradual, oferecendo alimento vivo durante pelo menos dois dias após a inserção da dieta seca, pois, quando a transição foi realizada de forma abrupta (retirada do plâncton e oferta da ração), o rendimento foi menor. No entanto, alguns autores, como Cahu \& Infante (2001), afirmam que o efeito das enzimas dos organismos presa facilitando a digestão das larvas ainda não pode ser considerado con- clusivo. Esses autores acreditam que, no momento em que as larvas apresentam abertura da boca, os organismospresa podem ser totalmente substituídos por uma dieta artificial.

A incapacidade de assimilar rações é provocada pela carência de enzimas digestivas, e não pela sua ausência. No início da alimentação, o sistema digestório já é funcional, mas sua estrutura e funcionalidade são simples; assim, ocorrem transformações até o trato digestório atingir a complexidade do adulto (Govoni et al., 1986). Vega-Orellana et al. (2006) observaram em larvas de dourado atividade de protease ácida a partir do terceiro dia, que aumentou gradualmente até o sétimo dia, indicando funcionalidade de estômago. Galvão et al. (1997) observaram que larvas de tainha com quatro dias de vida são capazes de digerir alimentos exógenos, apesar da baixa atividade proteolítica, resultante da atividade das enzimas tripsina, carbopeptidases A e B. No entanto, esses autores não constataram a existência de pepsina e quimiotripsina, cuja ausência dificulta a quebra das ligações peptídicas.

Galvão et al. (1997) sugeriram que as dietas contenham proteínas previamente hidrolisadas ou aminoácidos livres e que seja verificada a incorporação de enzimas purificadas na ração, como a pancreatina, testada por Tesser et al. (2006) em larvas de pacu P. mesopotamicus e por Kolkovski et al. (1997), em larvas de "seabass", D. labrax. Em D. labrax, a pancreatina ofertada com náuplios de artêmia afetou significativamente a composição corpórea da larva, embora não tenha afetado o crescimento.

A dependência do plâncton pode não ser necessariamente verdadeira para alguns Siluriformes, como o mandiamarelo, P. maculatus (Luz \& Zaniboni Filho, 2001), o jundiá, Rhamdia quelen (Cardoso et al., 2004) e o bagreafricano, Heterobranchus longifilis (Legendre et al., 1995).

Cardoso et al. (2004), trabalhando com larvas de jundiá siluriformes nativo da Região Sul do Brasil, verificaram que o uso de alimentos crus à base de fígado bovino e de aves proporcionou melhores resultados em comparação aos alimentos com farinha de fígado bovino e de ave e hidrolisados de peixe e de fígado de aves. Esses autores sugeriram que os piores resultados obtidos com o uso de farinha de fígado poderiam ser explicados pelas possíveis perdas de aminoácidos e açúcares redutores no processo de secagem e moagem, que, ao aquecerem, promoveriam a reação de Maillard. Ressalta-se que, no experimento de Cardoso et al. (2004), todos os alimentos continham levedura de cana, que não é plâncton, mas é organismo vivo. Além disso, os fígados crus, apesar de não serem organismos vivos, são 
alimentos frescos e preservam muitas características do organismo vivo. No trabalho com bagre-africano $(H$. longifilis), Legendre et al. (1995) utilizaram fígado e fermento (levedura).

Luz \& Zaniboni Filho (2001), cultivando larvas de P. maculatus alimentadas com ração e plâncton silvestre, não verificaram diferença no rendimento, na taxa de sobrevivência, no comprimento, no peso e na incidência de canibalismo. Esses autores destacaram que as larvas subiam até a superfície e nadavam ativamente entre as partículas de alimento para capturá-las. Entretanto, o experimento foi conduzido por cinco dias com larvas de 21 horas póseclosão, quando ainda apresentavam reduzida quantidade de reserva vitelínica. Então, essa igualdade nos rendimentos com as larvas de $P$. maculatus pode estar associada à sua capacidade de assimilar ração ou por se alimentarem das irmãs, canibalismo. Além disso, o período de cultivo foi curto e as larvas ainda tinham reservas energéticas suficientes para não ocorrer mortalidade em massa.

\section{Conclusões}

O zooplâncton de maior tamanho proporciona melhores índices de desempenho na larvicultura de pacamã e favorece a expressão do potencial de crescimento desta espécie. $\mathrm{O}$ fornecimento de ração não afetou o desempenho das larvas, evidenciando a baixa ou a falta de capacidade das larvas em digerir a ração ofertada. Entretanto, a ração diminuiu o $\mathrm{pH}$ e aumentou a condutividade elétrica da água, deteriorando sua qualidade, o que não afetou o rendimento das larvas.

\section{Agradecimento}

À jornalista Léa Cristina Vilela Sá Fortes Pedreira e à Senhora Elby Mattos Pedreira, pela revisão do texto. Ao Convênio CODEVASF/CEMIG, pelo apoio financeiro.

\section{Literatura Citada}

BEHR, E.R.; FURUYA, W.M.; FURUYA, V.R.B. et al. Efeito da densidade do copépode ciclopóide Mesocyclops longisetus na predação de larvas de pintado Pseudoplatystoma corruscans. Boletim do Instituto de Pesca, v.24, n.único, p.261-266, 1997

BOMBARDELLI, R.A.; HAYASHI, C.; MEURER, F. et al. Avaliação de rações fareladas e micropeletizadas para larvas de tilápia do Nilo (Oreochromis niloticus) - desempenho e efetividade da reversão sexual. Acta Scientiarum, v.26, n.2, p.197-201, 2003.

CAHU C.; INFANTE, J.Z. Substitution of live food by formulated diets in marine fish larvae. Aquaculture, v.200, n.1-2, p.161$180,2001$.
CARDOSO, A.P.; RADÜNZ NETO, J.; MEDEIROS, T.S. et al. Criação de larvas de jundiá (Rhamdia quelen) alimentadas com rações granuladas contendo fígados ou hidrolisados. Acta Scientiarum, v.26, n.4, p.457-462, 2004.

DABROWSKI, K. The feeding of fish larvae: present "state of the art" and perspectives. Reprodutive Nutritionale Dévelopment, v.24, n.6, p.807-833, 1984 .

DURAY, M.N.; ESTUDILLO, C.B.; ALPASAN, L.G. Larval rearing of the grouper Epinephelus suillus under laboratory conditions. Aquaculture, v.150, n.1-2, p.63-76, 1997.

FREGADOLLI, C.H. Laboratory analysis of predation by cyclopoid copepods on first-feeding larvae of cultured Brazilian fishes. Aquaculture, v.228, n.1-4, p.123-140, 2003.

GALVÃO, M.S.N.; YAMANAKA, N.; FENERICH-VERANI, N. et al. Estudos preliminares sobre enzimas digestivas proteolíticas da tainha MugiL platanus Günther, 1880 (Osteichthyes, Mugilidae) durante as fases larval e juvenile. Boletim do Instituto de Pesca, v.24, n.único, p.101-110, 1997.

GODINHO, A.L.; BRITO, M.F.G.; GODINHO, H.P. Pesca nas corredeiras de Buritizeiro: da ilegalidade à gestão participativa In: GODINHO, H.P.; GODINHO, A.L. (Eds.) Águas e peixes e pescadores do São Francisco das Minas Gerais. Belo Horizonte: PUCMinas, 2003. p.347-360.

GOVONI, J.J.; BOEHLERT, G.W.; WATANABE, Y. The physiology of digestion in fish larvae. Enviromental Biology of Fishes, v.16, n.1-3, p.59-77, 1986.

HUNTER, J.R. Feeding ecology and predation of marine fish larvae. In: LASKER, R. (Ed.) Marine fish larvae: morphology, ecology, and relation to fisheries. Washington: Washington Sea Grant Program, 1984. p.33-77.

KAMLER, E. Early life history of fish an energetics approach London: Chapman and Hall, 1992. 267p.

KOLKOVSKI, S.; TANDLER, A.; IZQUIERDO M.S. Effects of live food and dietary digestive enzymes on the efficiency of microdiets for seabass (Dicentrarchus labrax) larvae. Aquaculture, n.148, v.4, p.313-322, 1997.

LEGENDRE, M.; KERDCHUEN, N.; CORRAZE G. et al. Larval rearing of an African Catfish Heterobranchus longifilis (Teleostei, Clariidae): effect of dietary lipids on growth, survival and fatty acid composition of fry. Aquatic Living Resources, n.8, v.4, p.355-363, 1995 .

LINS, L.V.; MACHADO, A.B.M.; COSTA, C.M.R. et al. Roteiro metodológico para elaboração de listas de espécies ameaçadas de extinção: contendo a lista oficial da fauna ameaçada de extinção de Minas Gerais. Belo Horizonte: Fundação Biodiversitas, 1997. 55p.

LÓPEZ, C.M.; SAMPAIO, V.S. Sobrevivência e crescimento larval do pacamã Lopisilurus alexandri Steindachner 1876 (Siluriformes, Pimelodidae), em três densidades de estocagem em laboratório. Acta Scientiarium, v.22, n.2, p.491-494, 2000.

LUZ, R.K.; ZANIBONI-FILHO, E. Utilização de diferentes dietas na primeira alimentação do mandiamarelo (Pimelodus maculatus, Lacépéde), Acta Scientiarum, v.23, n.2, p.483489, 2001.

OLIVEIRA, A.M.M.S.; CONTE, L.; CYRINO, J.E.P. Produção de characiformes autócones. In: CYRINO, J.E.P.; URBINATI, E.C.; FRACALOSSI, D.M. et al. (Eds.) Tópicos especiais em piscicultura de água doce tropical intensiva. São Paulo: TecArt, 2004. p.217-238.

PEDREIRA, M.M.; SIPAÚBA-TAVARES, L.H. Efeito de cinco tratamentos alimentares em sistema de cultivo intensivo na sobrevivência de larvas de tambaqui Colossoma macropomum: resultados preliminares. In: REUNIÃO ANUAL DO INSTITUTO DE PESCA, 7., 1998, São Paulo. Anais... São Paulo: Instituto de Pesca, 1998. p.26-26.

PEDREIRA, M.M.; SIPAÚBA-TAVARES, L.H. Efeito de cinco tratamentos alimentares na sobrevivência e desenvolvimento de larvas de matrinxã Brycon cephalus em cultivo intensivo. In: CONGRESSO BRASILEIRO DE LIMNOLOGIA, 7., 1999, 
Florianópolis. Anais... Florianópolis: Sociedade Brasileira de Limnologia, 1999. v.2, p.593-593.

PEDREIRA, M.M.; SIPAÚBA-TAVARES, L.H. Effect of prey selection and ration addition on the rearing of piracanjuba larvae, Brycon orbignyanus. Boletim do Laboratório de Hidrobiologia, v.14-15, p.99-109, 2002.

PEDREIRA, M.M.; SIPAÚBA-TAVARES, L.H.; SILVA, R.C. Influência do formato do aquário na sobrevivência e no desenvolvimento de larvas de matrinxã Brycon cephalus (Osteichthyes, Characidae). Revista Brasileira de Zootecnia, v.35, n.2, p.1-5, 2006.

SANTOS, J.C.E.; SANTIAGO, K.B.; SAMPAIO, E.V. Desempenho de pós-larvas de pacamã Lophiosilurus alexandri, (Steindachner, 1876) submetidas a dois tipos de alimento vivo. In: CONGRESSO BRASILEIRO DE ENGENHARIA DE PESCA, 13., 2003, Porto Seguro. Anais... Porto Seguro: Federação das Associações de Engenheiros de Pesca do Brasil, [2003]. (CD-ROM)

SATO, Y.; CARDOSO, E.L.; AMORIM, J.C.C. Peixes das lagoas marginais do rio São Francisco a montante da represa de Três Marias (Minas Gerais). Brasília: Codevasf, 1987. 42p.

SATO, Y; FENERICH-VERANI, N.; GODINHO, H.P. Reprodução induzida de peixes da bacia do São Francisco. In: GODINHO, H.P.; GODINHO, A.L. (Eds.) Águas e peixes e pescadores do São Francisco das Minas Gerais. Belo Horizonte: PUCMinas, 2003. p.275-290.
SATO, Y.; GODINHO, H.P. Peixes da bacia do rio São Francisco. In: LOWE-McCONNELL, R.H. (Ed.) Estudos ecológicos de comunidades de peixes tropicais. (Trad.) São Paulo: EDUSP, 1999. p.410-413.

SATO, Y.; SAMPAIO, E.V. A ictiofauna na região do alto São Francisco, com ênfase no reservatório de Três Marias, Minas Gerais. In: NOGUEIRA, M.G.; HENRY, R.; JORCIN, A. (Eds.) Ecologia de reservatórios: impactos potenciais, ações de manejo e sistemas em cascata. São Carlos: RiMa, 2005. p.251-274.

SHÄFER, A. Fundamentos de ecologia e biologia das águas continentais. Porto Alegre: Editora da Universidade, 1985. $532 \mathrm{p}$.

SMERMAN, W.; CASTRO, J.G.D.; TOLEDO, J.J. et al. [2002] Larvicultura de Pintado (Pseudoplatistoma sp) em Alta-Floresta - Mato Grosso. Disponível em: <http://redalyc.uaemex.mx/ redalyc/pdf/500/50020101.pdf> Acesso em: 13/11/2006.

TESSER, M.B.; FLORES-QUINTANA, C.I.; CARNEIRO D.J. et al. Suplementação de enzimas exógenas em dieta microparticulada para larvicultura do pacu. Revista Brasileira de Zootecnia, v.35, n.6, p.2211-2218, 2006.

TUCKER JR., J.W. Marine fish culture. Norwell: Kluwer Academic Press, 1998. 750p.

VEGA-ORELLANA, O.M.; FRACALOSSI, D.M.; SUGAI, J.K Dourado (Salminus brasiliensis) larviculture: weaning and ontogenetic development of digestive proteinases. Aquaculture, v. 252 , n.2-4, p.484-493, 2006 